\title{
Coral bleaching from a single cell perspective
}

\author{
Daniel Aagren Nielsen $\mathbb{D}^{1} \cdot$ Katherina Petrou $\mathbb{D}^{1} \cdot$ Ruth D. Gates ${ }^{2}$
}

Received: 30 September 2017 / Revised: 18 January 2018 / Accepted: 26 January 2018 / Published online: 20 February 2018

(c) The Author(s) 2018. This article is published with open access

\begin{abstract}
Ocean warming is resulting in increased occurrence of mass coral bleaching; a response in which the intracellular algal endosymbionts (Symbiodinium sp.) are expelled from the coral host due to physiological stress. This detrimental process is often attributed to overproduction of reactive oxygen species (ROS) that leak out of the endosymbionts and causes damage to the host cell, though direct evidence validating this link is limited. Here, for the first time, we used confocal microscopy and fluorescent dyes to investigate if endosymbiont ROS production significantly and predictably affects physiological parameters in its host cell. Heat treatment resulted in a $60 \%$ reduction in coral symbiont density, a $\sim 70 \%$ increase in median endosymbiont ROS and a small reduction in photosystem efficiency $\left(F_{\mathrm{V}} / F_{\mathrm{M}}, 11 \%\right)$, indicating absence of severe light stress. Notably, no other physiological parameters were affected in either endosymbionts or host cells, including reduced glutathione and ROS-induced lipid peroxidation. Taken together, the increase in endosymbiont ROS could not be linked to physiological damage in either partner, suggesting that oxidative stress is unlikely to have been the driver for symbiont expulsion in this study.
\end{abstract}

\section{Introduction}

The global success of corals in tropical waters is underpinned by their symbiotic partnership with photosynthetic intracellular dinoflagellate microalgae (Symbiodinium sp.), which supply the animal host with photosynthetically fixed carbon in exchange for nutrients [1]. For this mutualistic association to prosper, corals need to balance energy expenditure (nutrient delivery to symbiont) with energy gain (fixed carbon from the symbiont). To achieve this, corals actively regulate their symbiont density both on a seasonal basis and in response to local environmental

These authors contributed equally: Daniel Aagren Nielsen, Katherina Petrou.

Electronic supplementary material The online version of this article (https://doi.org/10.1038/s41396-018-0080-6) contains supplementary material, which is available to authorized users.

Daniel Aagren Nielsen

danielaagrennielsen@gmail.com

1 School of Life Sciences, University of Technology Sydney, Sydney, Australia

2 Hawai'i Institute of Marine Biology, School of Ocean and Earth Science and Technology at the University of Hawai'i at Manoa, Hawai' i, USA conditions [2-4]. However, when conditions alter sufficiently to cause physiological stress, it can lead to a phenomenon known as coral "bleaching"; the whitening of corals due to detrimental breakdown of the coral symbiosis and consequent loss-of-symbiotic algae from the host tissue and/or loss-of-pigment [5, 6]. To date, numerous environmental triggers of coral bleaching have been identified including, but not limited to, changes in temperature and light $[7,8]$, as well as nutrient imbalance $[9,10]$. However, complete understanding of the cellular mechanisms responsible for the breakdown of the symbiotic partnership is still lacking [11, 12].

In recent decades, increasing ocean temperatures have resulted in extensive loss-of-coral cover around the globe, reflecting post bleaching mortality [13]. This mass bleaching mortality is considered to be driven by photo-oxidative stress in the coral symbionts following temperature and light-induced damage to the photosystem [11, 14, 15]. According to the oxidative theory of coral bleaching, reactive oxygen species (ROS) produced through activity of the damaged photosynthetic machinery in the symbiont, leak into the host cell where it overwhelms the antioxidant system and causes damage to the host tissue [14, 15]. By expelling the symbiont, and thus the source of excess ROS, the host minimises the level of physiological damage under suboptimal environmental conditions [11, 16]. In cells, ROS are produced in the mitochondria and chloroplasts [17], 


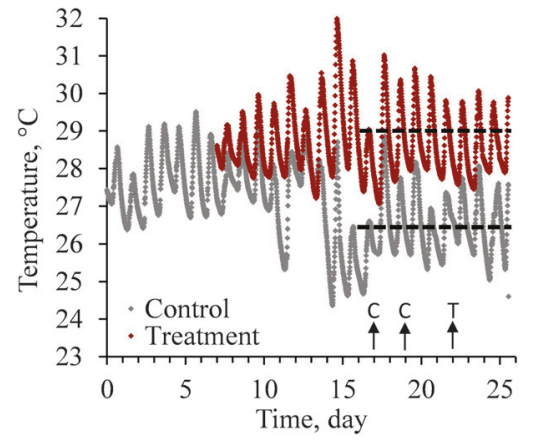

Fig. 1 Temperature throughout the experiment. Grey and red lines: smoothed average of temperature in control and heated mesocosms, respectively. Coral fragments to undergo heat treatment were transferred to heated mesocosms on day 7 (onset of red trace). Arrows indicate days of analysis of control (days 17 and 19) and heat-treated fragments (day 22). Analysis of control fragments were carried out over the 3 days due to processing time constraints

where superoxide dismutase (SOD) works as the first line of defence in an important detoxification process [18]: the SOD converts superoxide anions $\left(\mathrm{O}_{2}^{-}\right)$, produced through one-electron reduction of $\mathrm{O}_{2}$, to the more stable hydrogen peroxide $\left(\mathrm{H}_{2} \mathrm{O}_{2}\right)$. To limit build-up of this cytotoxic compound, $\mathrm{H}_{2} \mathrm{O}_{2}$ is quickly reduced to harmless $\mathrm{H}_{2} \mathrm{O}$ and $\mathrm{O}_{2}$ by a broad arsenal of enzymatic and non-enzymatic antioxidants, including the high-affinity glutathione peroxidase (GPx) in conjunction with the co-factor glutathione, as well as ascorbate peroxidase (APX) and the low affinity catalase enzyme. However, under sub-optimal conditions (i.e., stressful) the local concentration of ROS can increase because of an offset between production and this dissipation mechanism. If the production of ROS is higher than the reductive potential of the antioxidant system, ROS may lead to several forms of cellular damage, including lipid peroxidation (membrane damage), protein oxidation and DNA degeneration [17].

The proposed importance of ROS in the physiological mechanism leading to mass coral bleaching is buoyed by evidence of temperature and light-induced production of ROS and reactive nitrogen species (RNS), antioxidant upregulation in both host and symbionts [15, 19-22], as well as a reduction of bleaching in presence of exogenously applied antioxidants [23]. Additionally, observations of mitochondria and chlorophyll degradation in isolated Symbiodinium [24, 25] and host tissue [26] support the role of severe physiological disorder in the bleaching process. However, despite significant effort over recent decades to verify the implication of ROS in coral bleaching, the extent of the relationship between symbiont ROS production and host physiological stress remains ambiguous. In particular, recent work has found the host to increase its antioxidants in response to heat stress prior to its symbionts and preceding photo-physiological decline [27, 28], demonstrating that photosystem stress may in fact be a late stage response in the bleaching process and not the initial driver of expulsion. Irrespective, the initial increase in host antioxidants could suggest a role of ROS in the early bleaching process, which remains to be further investigated.

One of the major obstacles to uncovering the mechanisms of coral bleaching is the inherent difficulty of separating the response of the host from that of the intracellular symbiont. Til now, this has been achieved only by physically separating the host and symbionts, destroying the host tissue in the process and consequently averaging analyses across multiple host cell types, most of which are nonsymbiotic. However, the progressive loss-of-symbionts from coral tissue during bleaching suggests that it happens on a cell by cell basis, highlighting that coral bleaching is fundamentally a single-celled process occurring on a massive scale. Therefore, averaging measurements across cell types may result in substantial bias or a reduction in the observed responses of the specific cells directly involved in the bleaching process.

To adequately separate the stress response of the symbiont from that of the host and to attempt to identify any resulting interactions between the two partners, we propose that it is necessary and advantageous to address the question at the scale of the individual cell. Here we explore, for the first time, the process of coral bleaching at the single-cell level, utilising intact symbiotic cells (host with symbionts) to study heat-induced ROS production and its metabolic consequences in the important reef-building coral Pocillopora damicornis. Measuring key stress indicators in $>1700$ individual cells using confocal microscopy, we aimed to disentangle the thermal stress responses of these closely entwined symbiotic partners.

\section{Material and methods}

\section{Coral collection and experimental protocol}

Three colonies of Pocillopora damicornis were collected from Kaneohe Bay, Oahu, Hawai' $i$ in July 2015 and maintained in mesocosm tanks $\left(3 \mathrm{~m}^{3}\right)$ with constant flow through of bay seawater $\left(\sim 180 \mathrm{~L} \mathrm{~h}^{-1}\right)$. To minimise lightonly-induced damage to the photosystem (isolating the effect of thermal stress), corals were kept shaded to a midday maximum of $\sim 400 \mu \mathrm{mol}$ photons $\mathrm{m}^{-2} \mathrm{~s}^{-1}$ (Fig. S1), a light level well-above the initial minimum saturating irradiance $\left(I_{\mathrm{k}} ; \sim 248 \mu \mathrm{mol}\right.$ photons $\left.\mathrm{m}^{-2} \mathrm{~s}^{-1}\right)$ (Fig. S2, Table S1). While the reduced light level does not represent the common scenario for exposed corals on a shallow reef flat, it may be considered ecologically relevant to corals living in somewhat more shaded areas or in deeper water [29]. Coral colonies were acclimated for 2 days before being cut into 
Table 1 Staining characteristics and microscope settings for each fluorescent dyes used in this study

\begin{tabular}{|c|c|c|c|c|c|c|c|}
\hline \multicolumn{3}{|l|}{ Dye characteristics } & \multicolumn{2}{|l|}{ Method } & \multicolumn{3}{|c|}{ Microscope settings } \\
\hline Name & Target & Ex./Em. nm & $\begin{array}{l}\text { Final conc. } \\
\mu \mathrm{M}\end{array}$ & Time min & Laser nm & Laser intensity $\%$ & Collection range $\mathrm{nm}$ \\
\hline $\mathrm{CM}-\mathrm{H}_{2}$ DCFDA & ROS (broad) & $492 / 520$ & 20 & 20 & 488 & 1.5 & $510-550$ \\
\hline $\mathrm{mBBr}$ & Red. glutathione & $400 / 490$ & 50 & 20 & 405 & 1.0 & $430-510$ \\
\hline Image-iT & Lipid hydro-peroxides & $\begin{array}{l}581 / 590 \quad 488 / \\
510\end{array}$ & 10 & 20 & 561488 & 3.0 & $580-610$ \\
\hline Calcein violet $\mathrm{AM}$ & Esterase activity & $400 / 452$ & 2 & 20 & 405 & 1.0 & $410-490$ \\
\hline Rhodamine 123 & Mitochondrial activity & $511 / 534$ & 5 & 20 & 488 & 1.5 & $500-550$ \\
\hline- & Chlorophyll auto FL & $580 / 650$ & - & - & 561 & 0.1 & $621-680$ \\
\hline
\end{tabular}

Laser settings and imaging time were optimised to minimise photo-activation/bleaching of the respective dye, as well as auto-fluorescence (except when measuring chlorophyll). All settings were kept constant throughout the experiment

All dyes were obtained from Life Technologies corp., USA

$\sim 3 \mathrm{~cm}$ fragments and fastened to a grid using Epoxy (Fig. S3). After 1 week of pre-conditioning to control conditions $\left(27.6 \pm 0.8^{\circ} \mathrm{C}\right)$, a sub-set of coral fragments from each colony were transferred to separate mesocosms $\left(3 \mathrm{~m}^{3}\right)$ with lower flow and higher thermal heat input via exposure to direct sun (corals remained shaded: Fig. S1), resulting in a daily mean temperature of $\sim 29^{\circ} \mathrm{C}$ with a mid-day maximum of $30-31^{\circ} \mathrm{C}$ and a night time low of $27-28^{\circ} \mathrm{C}$ (Fig. 1). At the time, Kaneohe Bay was experiencing above average and increasing water temperatures, and on day 14 of the study it was deemed necessary to cool the flow through water for control colonies to the long-term average temperature for July $\left(26-27^{\circ} \mathrm{C}\right.$, National Oceanic and Atmospheric Administration's National Data Buoy Center [Station MOKH1-1612480-Mokuoloe, HI, US]) (Fig. 1). A very high-tank-volume-to-coral-biomass ratio ( 6000:1) and significant water flow minimised any tank effects and pseudoreplication by ensuring identical treatment conditions to all coral fragments within each mesocosm. Heat treated coral fragments were analysed once they were visually paler than the control fragments, but before complete bleaching, which otherwise would have left too few endosymbiotic cells to analyse. To account for biological variability between colonies, one coral fragment was extracted (see below for methodology) from each coral replicate for each treatment and dye used. However, in subsequent analysis replication was considered to be at the single-cell level. Due to time constraints as a result of the staggered extraction protocol (see below), control and treatment coral fragments were analysed on subsequent days (Fig. 1: $\mathrm{C}$ and T, respectively)

\section{Symbiont photosynthetic capacity and density}

Photosynthetic health of symbiont cells was monitored over time (Fig. S4) using a Pulse Amplitude Modulation fluorometer (PAM) (Diving PAM, Walz GmbH, Germany).
Minimum $\left(F_{\mathrm{O}}\right)$ and maximum $\left(F_{\mathrm{M}}\right)$ fluorescence of darkadapted (20 min after sunset) coral fragments were determined for each treatment and maximum quantum yield of Photosystem II $\left(F_{\mathrm{V}} / F_{\mathrm{M}}\right)$ calculated according to Schreiber [30]. On the day of sampling, photosynthetic capacity and symbiont cell density was measured on replicate coral fragments. Rapid light curves were carried out after sunset on replicate coral fragments with nine incrementing light levels $(54,91,136,184,288,396,606,896$ and $1335 \mu \mathrm{mol}$ photons $\mathrm{m}^{-2} \mathrm{~s}^{-1}$ ) applied for $30 \mathrm{~s}$ each before recording the light-adapted minimum $\left(F_{\mathrm{T}}\right)$ and maximum fluorescence $\left(F_{\mathrm{M}}{ }^{\prime}\right)$ values. The relative electron transport rates (rETR) were calculated as $\left.\left(F_{\mathrm{M}^{\prime}}-F_{\mathrm{T}}\right) / F_{\mathrm{M}}{ }^{\prime}\right) * \mathrm{PAR}$ and photosynthetic parameters $\left(\mathrm{rETR}_{\max }, \mathrm{I}_{\mathrm{k}}, \alpha\right)$ determined from a double exponential function fitted to the data (Fig. S2) [31]. Symbiont density was determined by water picking coral tissue from individual fragments ( $n=3$ per treatment) into $5 \mathrm{~mL}$ of filtered sea water (FSW). The resulting tissue slurry was homogenised using a benchtop homogeniser and centrifuged at $\sim 350 \mathrm{RCF}$ for 2 min after which supernatant was discarded and the pellet of symbiont cells resuspended in 2.5-5.0 mL FSW. The cell concentration in each extract was determined by manual counting (repeated eight times) using a haemocytometer (Brightline, Hausser scientific) and normalised to the surface area of each coral fragment, which was measured using a standard waxing technique [32].

\section{Sample preparation}

A range of fluorescent dyes were used for semi-quantitative measures of general ROS $\left(\mathrm{CM}-\mathrm{CH}_{2} \mathrm{DCFDA}\right.$, reacts with a range of radicals including $\mathrm{HO}_{2}{ }^{\circ}, \mathrm{RO}^{\circ}, \mathrm{NO}_{2}{ }^{\circ}, \mathrm{CO}_{3}{ }^{--}, \mathrm{OH}^{\circ}$ and $\mathrm{ONOO}^{-}$[33], reduced glutathione (GSH) (Monobromobimane, $\mathrm{C}_{10} \mathrm{H}_{11} \mathrm{BrN}_{2} \mathrm{O}_{2}$, reacts with low-molecular weight reduced thiols, including the abundant glutathione) and lipid peroxidation (Image-iT: BODIPY 581/591 C11, fluorescence shift when oxidised by lipid hydroperoxides), 
as well as mitochondrial (Rhodamin123, accumulate in mitochondria in a membrane potential dependent manner) and esterase activity (Calcein AM, hydrolised by intracellular esterases to produce a fluorescent product) in the animal and symbiont cells. All dyes were obtained from Life Technologies, USA (see Table 1 for details). While the final concentration employed for the ROS dye CM$\mathrm{CH}_{2}$ DCFDA $(20 \mu \mathrm{M})$ was higher than recommended in the manufacturers manual $(1-10 \mu \mathrm{M})$, it was well within the range of use in other published studies $(25-50 \mu \mathrm{M})$ (i.e., [34-36]). To ensure all samples experienced similar environmental conditions prior to measuring, coral fragments were kept in a laboratory water bath at constant treatment temperature $\left(26\right.$ or $29^{\circ} \mathrm{C}$ for control and treatment, respectively) and an incident irradiance of $400 \mu \mathrm{mol}$ photons $\mathrm{m}^{-2} \mathrm{~s}^{-1}$ (blue and white LED, Hydra, C2 Development inc. USA) for $1 \mathrm{~h}$ prior to extraction. For each dye, endoderm cells were extracted from a coral fragment from each coral colony $(n=3)$. In order to ensure exact timing and uniformity of extraction, incubation, and measuring time, each coral fragment was processed individually, staggered by $\sim 25 \mathrm{~min}$ each (time frame of analysis). Symbiotic endoderm cells were extracted by placing a coral fragment in a $50 \mathrm{~mL}$ centrifuge tube containing $3 \mathrm{~mL}$ of $\mathrm{FSW}$ at treatment temperature and briefly striking the base of the tube against a hard surface to loosen the coral tissue from the skeleton. This resulted in the release of symbiotic endoderm cells while most of the outer connective tissue remained on the coral fragment (see Fig. S5 and corresponding figure text). The resulting slurry was pipetted into $1.5 \mathrm{~mL}$ Eppendorf tubes and gently pelleted at $~ 30 \mathrm{RCF}$ for $30 \mathrm{~s}$ followed by three washes in $1.5 \mathrm{~mL} \mathrm{FSW}$ to remove the more buoyant non-symbiotic cells. The remaining cells were resuspended in $0.5 \mathrm{~mL} \mathrm{FSW}$ to which the respective dyes were added (see Table 1 for final concentrations). For all dyes, cells were incubated in the dark at treatment temperature for $20 \mathrm{~min}$, washed twice as described above and resuspended in $50 \mu \mathrm{L}$ of FSW for microscopy analysis.

\section{Confocal fluorescence imaging}

To measure fluorescence of symbionts and host cells a laser scanning confocal microscope (LSM 710, Zeiss, Oberkochen, Germany) equipped with a temperature controlled environmental chamber (Incubator Xl S Examiner, Zeiss, Oberkochen, Germany) was employed. The confocal capability was necessary to visualise the fluorescence inside the symbiont cells, which is otherwise obscured by the dense layer of chloroplast present in these algae (absorption from chlorophyll). Approximately $30 \mu \mathrm{L}$ of cell suspension was transferred to a pre-heated microscope slide and symbiotic cells located manually under low-intensity visible light. Imaging of fluorescence was done at a total of $\times 630$ magnification (Zeiss Plan-apochromat $63 \times / 1.40$ Oil DIC M27 lens) using fixed collection ranges and laser intensities (Table 1) and the following microscope and imaging acquisition settings (optimised for speed): pinhole size: 1.51 AU, Image resolution: $512 \times 512(135 \times 135 \mu \mathrm{m})$, pixel dwell $1.58 \mu \mathrm{s}$, no averaging, $\mathrm{z}$-thickness $\sim 1.0 \mu \mathrm{m}$. For ease of identification and consistency, only host cells containing two symbionts were included as representatives of intact endosymbiotic cells. Non-symbiotic (ex-symbiont) cells were identified visually as chlorophyll containing cells with no discernible host membrane and no dye fluorescence external to the symbiont membrane. Due to inefficient dye penetration through the symbiosome membrane, no mitochondrial or esterase information could be obtained from endosymbionts. Auto-fluorescence, light-induced bleaching/activation of dye, as well as pixel-saturation during imaging was avoided by optimising microscope settings using controls of dead (killed by heating to $75^{\circ} \mathrm{C}$ for $5 \mathrm{~min}$ ) and live host and symbiont cells with and without dye.

\section{Fluorescence analysis}

Total fluorescence for the host and symbiont cells was measured using the FIJI package of the open source image software ImageJ [37]. Prior to quantification, the background fluorescence was subtracted from each layer of the respective image stack, measured in four locations around the cell in each layer and calculated as the mean fluorescence $+2 \times$ standard deviation (S.D.) $(n=4)$. Each cell type (host and symbionts) was subsequently individually measured in each layer of the image stack and total fluorescence for each calculated by summing all respective measurements (Supplementary Fig. S6). To ensure maximal precision, each region of interest was selected and inspected manually for all images (totalling $>18,000$ images across $>1700$ cells). Mitochondria were measured using a custom made ImageJ macro detecting each mitochondria in each layer of the image stack using the 'find peaks' function with outlining of each mitochondria based on a fixed intensity cutoff. Macro settings were kept constant for all treatments ensuring fixed thresholds and sampling parameters for all cells across type and treatment.

\section{Statistical analyses}

After confirming homoscedasticity and normality, a paired $t$-test was used to determine significant differences in $F_{\mathrm{V}} / F_{\mathrm{M}}$ and cell density between control and heat-treated corals at $\alpha$ $=0.05$. Comparison of distributions of fluorescence in cell populations from different treatments were carried out using the non-parametric two sample Kolmogorov-Smirnov (KS), where changes were considered significant at $P<$ 0.05. In addition, pairwise comparison of the median 

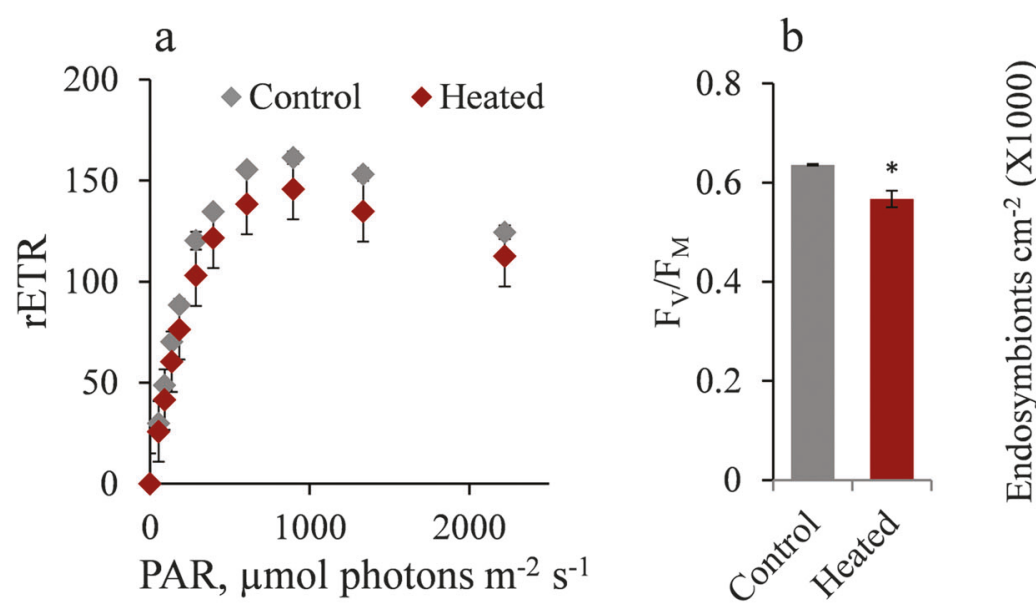
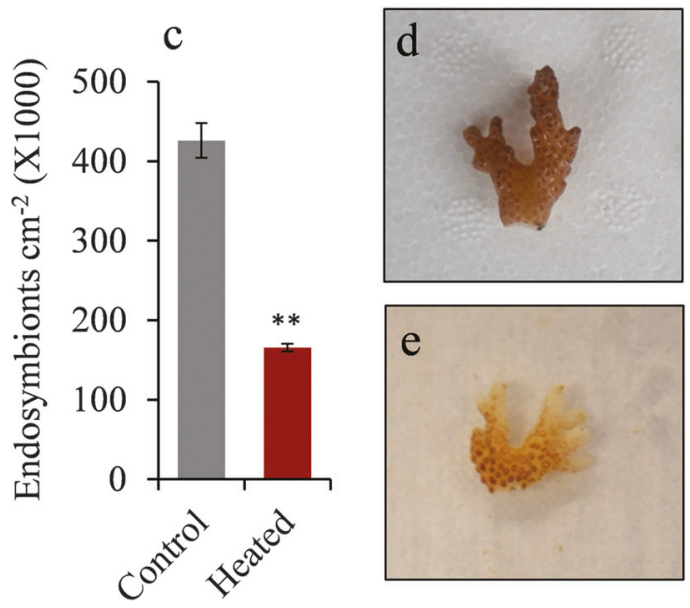

Fig. 2 Physiological characteristics of coral symbionts after experimental treatment. a Relative electron transport rate of coral symbionts at different levels of photosynthetically active radiation (PAR). b Maximum quantum yield of PSII $\left(F_{\mathrm{V}} / F_{\mathrm{M}}\right)$ of symbionts in coral tissue. c Symbiont cell density in coral tissue. d Example of control coral

fluorescence in cell populations from different treatments for each colony replicate were carried out using a paired $t$ test. For ease of visualisation, pooled data from all three replicate colonies are shown. To account for the presence of heteroscedasticity, Spearman's rank correlation was used to test for covariance between host and symbiont fluorescence. Geometric linear regressions of significant correlations between host and endosymbiont fluorescence were included for visual aid to highlight directionality and differences in correlations between treatments. Statistical tests were done using the R software package and Minitab (v.15; Minitab Inc. USA).

\section{Results}

After 2 weeks at elevated temperature, there was no significant difference in relative electron transport rates or minimum saturating irradiance (Fig. 2a; Table S1); however, there was a significant decline in the light utilisation efficiency of heat-treated symbionts from $\sim 0.64$ to 0.56 (Paired $t$-test, $T(2)=4.98, P=0.038$, Table S1). Similarly, the maximum quantum efficiency of Photosystem II $\left(F_{\mathrm{V}} /\right.$ $\left.F_{\mathrm{M}}\right)$ of the symbionts had declined in the heat-treated corals by $-11 \% \pm 2.5 \%$ (SD) (Paired $t$-test, $T(2)=7.65, P=$ 0.017 , Fig. 2b). A concomitant decline in cell density of $60 \%$, from $4.3 \times 10^{5} \pm 2.2 \times 10^{4}$ cells cm $^{-2}$ to $1.7 \times 10^{5} \pm$ $4.7 \times 10^{3}$ cells $\mathrm{cm}^{-2}$, verified that active bleaching was taking place (Paired $t$-test, $T(2)=14.76, P=0.005$, Fig. 2c) and distinct paling of the coral tissue was evident (Fig. 2d, e).

The high resolution of the confocal images allowed for easy separation of the host and endosymbiont cells (Fig. 3). fragment and e example heat-treated coral fragment. Error bars indicate standard error (SE, $n=3$ ). Stars indicate significant difference from control $(* P<0.05, * * P<0.01)$. Note, error bars for control in a and $\mathbf{b}$ are too small to be visible in this plot

Overall, host cell populations exhibited no changes in ROS, reduced glutathione (GSH), lipid peroxidation, mitochondrial activity (Fig. 4; Table S2) or esterase activity (Fig. S7; Table S2) with heat stress. Elevated temperatures lead to a significant increase in ROS in the endosymbiont cell population (median increase 69\%) (KS: $D=0.136, P=$ 0.0049), however, no differences were observed between cell populations for GSH or lipid peroxidation ratio (Fig. 4). Because of the possibility that the endosymbionts remaining in the coral tissue were all healthy and therefore would not exhibit signs of stress, we included in our investigation Symbiodinium cells that were not enclosed in a host cell and therefore might have been recently expelled (hereafter termed "ex-symbionts") (Fig. 3). In general, we found that ex-symbiont cells exhibited the same physiological responses as their non-expelled counterparts (Fig. 4), with a significant increase in ROS (median increase of 100\%) (KS: $D=0.523, P<0.0001)$, but no change in GSH or lipid peroxidation with heat treatment. Additionally, heat treatment had no effect on mitochondrial activity of the exsymbionts. In all cases, paired $t$-test on the population medians support the KS results (Table S2).

Associations between the metabolic response of the host and its respective symbionts were investigated using Spearman's ranked correlations on the pooled single-cell data (Fig. 5). We found a weak correlation $(\rho=0.26$, $\mathrm{d} f=$ $80, P=0.0196$ ) between host and endosymbiont ROS fluorescence in pooled control cells; however, there was no correlation when colonies were analysed individually (Table S3). We found a significant relationship between the host and endosymbiont ROS fluorescence in the heattreated cells $(\rho=0.51, \mathrm{~d} f=52, P=0.0001$, Fig. 5a), driven by the presence of a small number of highly fluorescent 


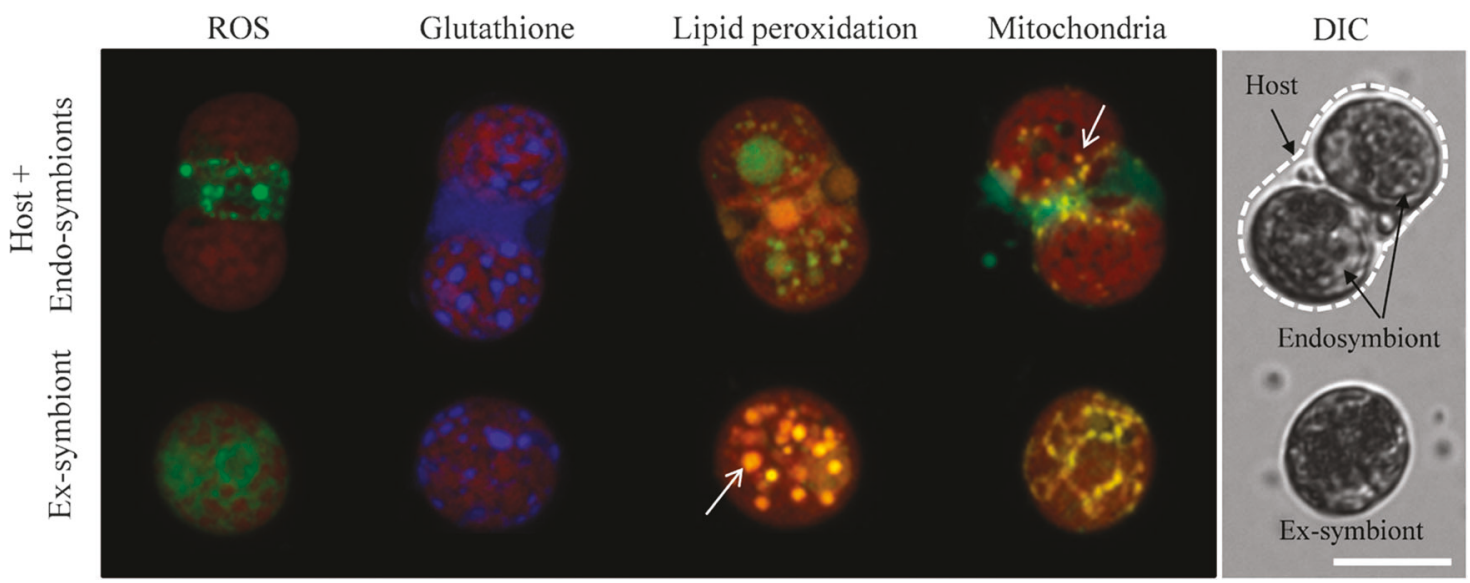

Fig. 3 Laser scanning confocal images (maximum projections) of endosymbiotic host cells with endosymbionts (top) and ex-symbionts (bottom), imaged after incubation with fluorescent dyes. Only cells from control groups are shown. Chlorophyll auto-fluorescence is shown in red. Left to right: $\mathrm{CM}-\mathrm{H}_{2}$ DCFDA (ROS, green), $\mathrm{mBBr}$ (reduced glutathione, blue), Image-iT (lipid peroxidation, yellow/green ratio), Rhodamin 123 (mitochondrial activity, yellow) and Calcein AM (esterase, teal). Arrows indicate individual mitochondria (top) and lipid body (bottom). Far right: grey scale differential interference contrast images (DIC), white stippled line outlines host cell membrane (top). Scale bar $=10 \mu \mathrm{m}$

bleaching) (Fig. 2). Consistent with previous studies on free-living Symbiodinium sp. exposed to acute heat stress [38, 39], elevated temperatures resulted in increased ROS production by the endosymbionts (Fig. 4) and a significant but minor decline in the maximum quantum yield of photosystem II (PSII) $\left(F_{\mathrm{V}} / F_{\mathrm{M}}\right.$, Fig. 2b). This decline may have been driven by production of singlet oxygen $\left({ }^{1} \mathrm{O}_{2}\right)$ in the chloroplasts, which is thought to be the most important ROS responsible for light-induced loss-of-PSII activity [40], however, the relatively small change in $F_{\mathrm{V}} / F_{\mathrm{M}}$ indicates that the photosystem was not severely compromised at this stage in the bleaching process. An increase in endosymbiont ROS production to the extent where a significant proportion of non-quenched ROS leaks into the host would be expected to be accompanied by damage to cellular components and changes to the antioxidant capacity of the cell. Yet, we found no additional signs of ROS-related physiological stress (Fig. 4). We observed no consistent reduction in the fluorescence of the Monobromobimane dye $(\mathrm{mBBr})$, suggesting that the pool of reduced glutathione (GSH) was maintained. Glutathione plays a crucial role in the cells antioxidant system, where it is oxidised by ROS to glutathione-disulfide (GSSG) directly (chemically) or enzymatically through the action of ascorbate and/or glutathione peroxidases (APX and GPX, respectively) [41]. Because of its paramount role in this redox cycle, GSH is quickly re-generated by reduction of GSSG with NADPH and glutathione reductase (GR) to maintain the cells redox state [41]. In Symbiodinium, sub-lethal heat stress has been shown to increase activity of GR, resulting in maintenance of the GSH pool despite increased reactive oxygen production [42]. However, this protective mechanism collapsed under more severe heat stress [42], and as such, any
In this study, prolonged heat stress of Pocillopora damicornis resulted in significant loss-of-symbionts (i.e., 
Fig. 4 Violin plots of $\log$ transformed cumulated fluorescence intensity and relative lipid peroxidation ratio distribution in pooled cell populations from control and heat-treated coral colonies. The lipid peroxidation values are shown as relative to the mean ratio of the respective control population to account for a significant expulsion effect. Black dot denotes the median of each group. Stippled line represents median value of control treatment for comparison. Stars indicate significant difference from control $(* P<0.05)$
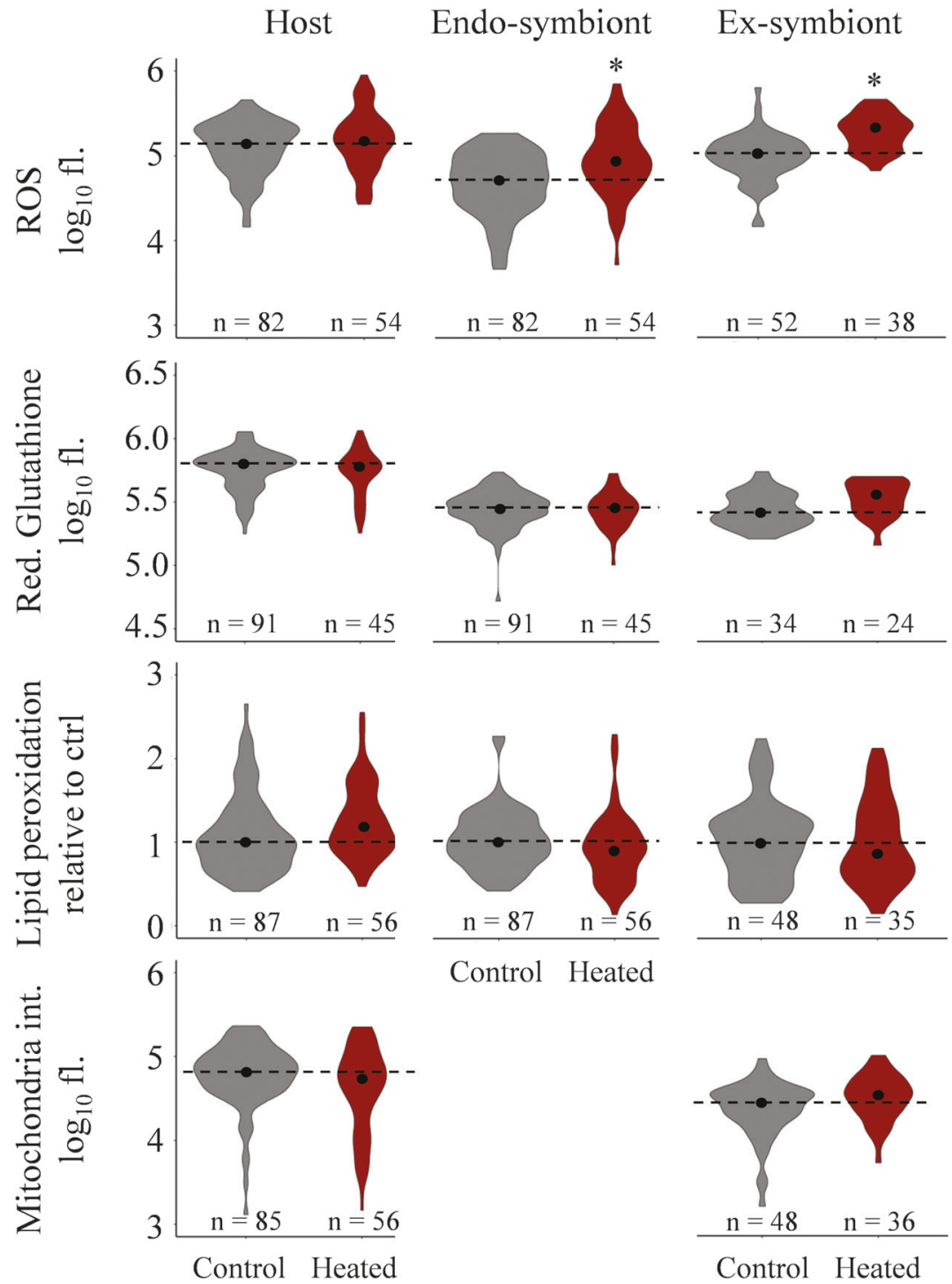

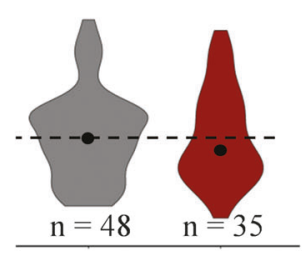

Control Heated

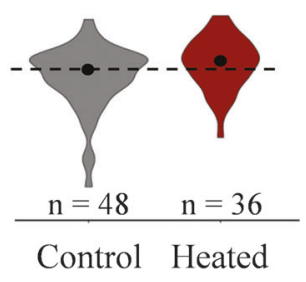

significant reduction in the level of GSH can be considered a strong indicator for excessive oxidative stress. In support of the lack of change in the glutathione pool, we found no evidence for ROS-induced damage through lipid peroxidation (Fig. 4), which is considered the principle molecular mechanism involved in the oxidative damage to cell structures [43]. Also, we observed no significant decline in relative electron transport rates of PSII (Fig. 2a) and no change in the level of chlorophyll fluorescence per cell volume, indicating little or no chlorosis (Fig. S8). Taken together, these data strongly suggest that the symbiont antioxidant system was effective at protecting itself against uncontrolled oxidative damage despite the substantial, heatinduced increase in steady-state ROS content.

The presence of "free" symbionts (here termed "exsymbionts") in coral tissue has been described previously, where non-host associated symbionts were found to account for up to $30 \%$ of the total symbiont count within the tissue of naturally bleached corals [24]. While it was not possible to determine whether these cells had recently been expelled from a host cell or if they were non-symbiotic cells residing freely within the coral host, the ex-symbiont cells were found to contain more lipid bodies than endosymbiotic cells (2-3×, data not shown), showing that, while a fraction of the cells may have been released from their hosts during the extraction procedure, most of the cells were physiologically different from the remaining endosymbionts. Other studies have found that temperature stress increases lipids and fatty acids in endosymbiont [44] and expelled symbionts (Petrou $\mathrm{K}$, personal communication), which demonstrates that expulsion of endosymbionts may be correlated with an increase in lipids. This supports the notion that the exsymbionts observed here may indeed have been expelled from host cells but not yet excluded from the coral tissue. Despite a higher median increase in ROS production ( $100 \%$ in pooled cells) with heat treatment (Table S4), the 

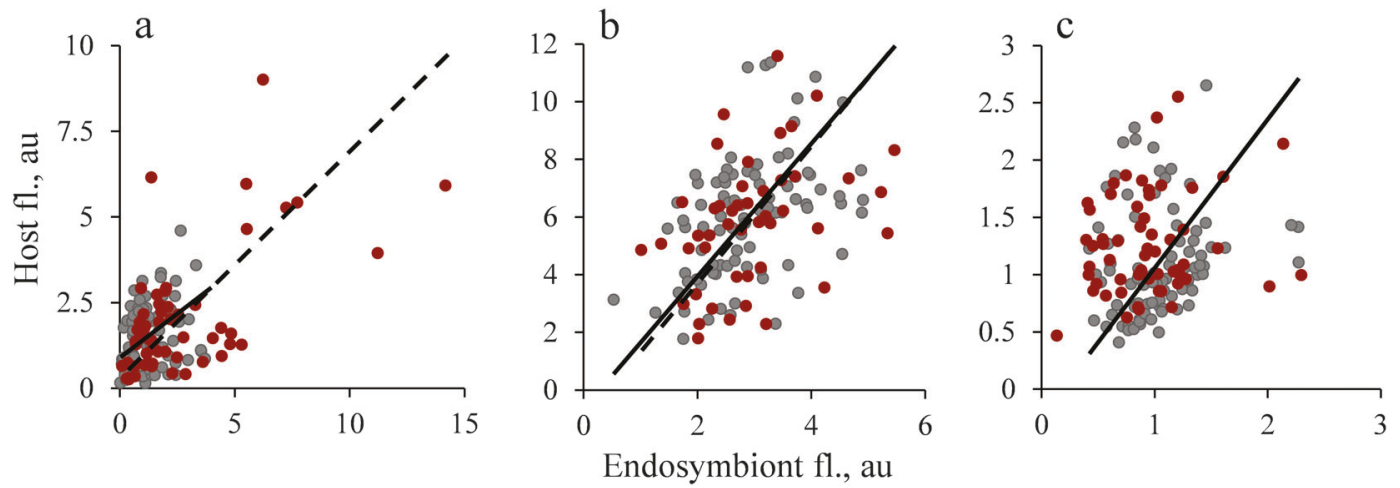

Fig. 5 Host versus endosymbiont fluorescence from a. Reactive oxygen (arbitrary units, au $\left.\times 10^{-3}\right)$, b Reduced glutathione $(\mathrm{GSH})(\mathrm{au} \times 10$ ${ }^{-3}$ ) and c lipid peroxidation (relative fluorescence ratio) for control (grey) and heat-treated (red) endosymbiotic cells. Black lines represent

ex-symbionts did not exhibit significant changes to other ROS-related physiological parameters measured here. Additionally, heat-treated ex-symbionts showed no consistent changes to mitochondrial activity as measured via proton-gradient dependent fluorescence. Given the high content of poly-unsaturated fatty acids and peroxidation catalysts, mitochondria are specific targets for lipid peroxidation damage, which may reduce the electron transfer rate and thus overall activity [45]. As such, the lack of change with heat treatment substantiates the results of little overall ROS-related physiological stress in these cells, and corroborates the results from the endosymbiont data. Importantly, these data do not preclude that under scenarios in which photosystem damage does occur, ROS could be an important trigger for bleaching due to the breakdown of important cellular and/or symbiotic functions, as suggested by the oxidative theory of coral bleaching. Instead, it highlights that bleaching may occur well before the onset of photosystem damage in the symbionts, perhaps as a result of alterations to the host-regulated nitrogen input to the symbionts as a consequence of physiological stress in the host $[9,46]$.

With the exception of a few individual cells, the heat treatment did not significantly increase the ROS concentration in the host, although, we cannot exclude the possibility of upregulation of ROS that is not detected by the dye employed. For instance, the important cellsignalling molecule NO has previously been shown to increase in corals in response to heat stress [47], but is not detected by $\mathrm{CM}-\mathrm{H}_{2} \mathrm{DCFDA}$. Similar to the ex-symbionts, we observed no consistent changes to the total mitochondrial fluorescence in the host cells (Fig. 4), indicating that the heat treatment employed in this study had little general effect on mitochondrial activity, and this was supported by the esterase activity showing that cell viability was retained [48]. This contrasts with previous studies that showed lossof mitochondrial integrity [26] and caspase-induced geometric linear regressions of significant correlations (full: control, stippled: heat-treated) and are included to highlight directionality and differences in correlations between treatments

apoptosis [49] in host cells in response to acute heat stress. However, the extreme ramping $\left(6-7^{\circ} \mathrm{C}\right.$ over a few hours) and sustained high temperatures $\left(32-33^{\circ} \mathrm{C}\right.$ for $\left.\geq 24 \mathrm{~h}\right)$ employed in these studies likely exacerbated the extent of damage to cellular components by not allowing time for adequate metabolic adjustments, including de novo synthesis of heat shock proteins [50]. The importance of heating rates and how it might influence the severity of the bleaching response has been discussed previously [28, 51]. Given the minimal effect on the physiological state of host cells in the present study, it indicates that little if any ROSinduced damage had occurred despite the prolonged incubation at increased temperature and natural light cycles.

The observed correlation between host and endosymbiont ROS in the heat-treated cells (Fig. 5a) may be explained either by a joint increase in net ROS due to metabolic stress in both partners simultaneously or indeed by diffusive transfer of ROS from one symbiotic partner to the other. However, based on the available data it is not possible to determine which of these mechanisms are more likely. While the pooled control cells only showed a weak correlation between host and symbiont ROS, heat treatment resulted in the generation of a sub-population $(\sim 15 \%$ of total) of highly fluorescent cells from two of the three coral replicates; indicative of high-ROS production. From this it is tempting to propose that the bleaching process is in fact driven by a small but continuously replenished subpopulation of cells reaching a stress-threshold resulting in the expulsion of the symbiont. This would explain the difficulty in obtaining consistent results when investigating coral bleaching using whole-tissue techniques, as the changes in such a relatively small population of cells within a larger pool of less affected cells would invariably reduce the overall observed response. However, the same pattern was not observed for reduced glutathione where the correlation between symbiont and host remained unchanged with no formation of sub-populations (Fig. 5b). 
The data presented here are the first of their kind to directly target the link between ROS-related physiological variables of the coral endosymbiont with that of its respective host cell at the cell-cell interface. The results show that the coral endosymbionts are not severely compromised by heat-induced ROS production, and emphasise that, in the absence of severe photosystem damage, ROS leakage from the endosymbiont to the host and subsequent ROS-induced damage is not likely to be the initial trigger for symbiont expulsion during heat-induced bleaching.

Acknowledgements We would like to thank Dr Hollie Putnam and Ms Jen Davidson for their technical support during this study. We would also like to acknowledge Dr Christian Evenhuis for his helpful input on data analyses, as well as the constructive comments from the three anonymous reviewers. This work was partly funded by an Early Career Research Grant (UTS) awarded to D.A.N. and K.P. During this work K.P. was funded by a Chancellor's Postdoctoral Research Fellowship (UTS). Corals were collected under US permit SAP2016-39 granted to K.P.

Author contributions Conceptualisation, methodology, investigation, writing - original draft: D.A.N and K.P.; formal analysis, visualisation: D.A.N and K.P.; writing-review and editing: K.P., D.A.N., and R.D.G.; funding acquisition, resources: K.P. and R.D.G.

\section{Compliance with Ethical Standards}

Conflict of interest The authors declare that they have no conflict of interest.

Open Access This article is licensed under a Creative Commons Attribution-NonCommercial-NoDerivatives 4.0 International License, which permits any non-commercial use, sharing, distribution and reproduction in any medium or format, as long as you give appropriate credit to the original author(s) and the source, and provide a link to the Creative Commons license. You do not have permission under this license to share adapted material derived from this article or parts of it. The images or other third party material in this article are included in the article's Creative Commons license, unless indicated otherwise in a credit line to the material. If material is not included in the article's Creative Commons license and your intended use is not permitted by statutory regulation or exceeds the permitted use, you will need to obtain permission directly from the copyright holder. To view a copy of this license, http://creativecommons.org/licenses/by-nc-nd/4.0/.

\section{References}

1. Yellowlees D, Rees TAV, Leggat W. Metabolic interactions between algal symbionts and invertebrate hosts. Plant Cell Environ. 2008;31:679-94.

2. Cunning R, Vaughan N, Gillette P, Capo TR, Mate JL, Baker AC. Dynamic regulation of partner abundance mediates response of reef coral symbioses to environmental change. Ecology. 2015;96:1411-20.

3. Stimson J. The annual cycle of density of zooxanthellae in the tissues of field and laboratory-held Pocillopora damicornis (Linnaeus). J Exp Mar Biol Ecol. 1997;214:35-48.

4. Fitt WK, McFarland FK, Warner ME, Chilcoat GC. Seasonal patterns of tissue biomass and densities of symbiotic dinoflagellates in reef corals and relation to coral bleaching. Limnol Oceanogr. 2000;45:677-85.
5. Glynn PW. Coral-reef bleaching in the 1980s and possible connections with global warming. Trends Ecol Evol. 1991;6:175-9.

6. Hoegh-Guldberg O, Bruno JF. The impact of climate change on the world's marine ecosystems. Science. 2010;328:1523-8.

7. Brown BE. Coral bleaching: causes and consequences. Coral Reefs. 1997;16:S129-S138.

8. Lesser MP, Farrell JH. Exposure to solar radiation increases damage to both host tissues and algal symbionts of corals during thermal stress. Coral Reefs. 2004;23:367-77.

9. Pogoreutz C, Radecker N, Cardenas A, Gardes A, Voolstra CR, Wild C. Sugar enrichment provides evidence for a role of nitrogen fixation in coral bleaching. Glob Change Biol. 2017;23:3838-48.

10. Rosset S, Wiedenmann J, Reed AJ, D'Angelo C. Phosphate deficiency promotes coral bleaching and is reflected by the ultrastructure of symbiotic dinoflagellates. Mar Pollut Bull. 2017;118:180-7.

11. Weis VM. Cellular mechanisms of Cnidarian bleaching: stress causes the collapse of symbiosis. J Exp Biol. 2008;211:3059-66.

12. Douglas AE. Coral bleaching-how and why? Mar Pollut Bull. 2003;46:385-92.

13. Spalding MD, Brown BE. Warm-water coral reefs and climate change. Science. 2015;350:769-71.

14. Lesser MP, Stochaj WR, Tapley DW, Shick JM. Bleaching in coral-reef Anthozoans-effects of irradiance, ultraviolet-radiation, and temperature on the activities of protective enzymes against active oxygen. Coral Reefs. 1990;8:225-32.

15. Downs CA, Fauth JE, Halas JC, Dustan P, Bemiss J, Woodley CM. Oxidative stress and seasonal coral bleaching. Free Radic Biol Med. 2002;33:533-43.

16. Smith DJ, Suggett DJ, Baker NR. Is photoinhibition of zooxanthellae photosynthesis the primary cause of thermal bleaching in corals? Glob Change Biol. 2005;11:1-11.

17. Freeman BA, Crapo JD. Free-radicals and tissue-injury. Lab Invest. 1982;47:412-26.

18. Fridovich I. Biology of oxygen radicals. Science. 1978;201: 875-80.

19. Hawkins TD, Davy SK. Nitric oxide production and tolerance differ among Symbiodinium types exposed to heat stress. Plant Cell Physiol. 2012;53:1889-98.

20. Mydlarz LD, Jacobs RS. An inducible release of reactive oxygen radicals in four species of gorgonian corals. Mar Freshw Behav Physiol. 2006;39:143-52.

21. Sandeman IM. Fragmentation of the gastrodermis and detachment of zooxanthellae in symbiotic cnidarians: a role for hydrogen peroxide and $\mathrm{Ca}^{2+}$ in coral bleaching and algal density control. Rev De Biol Trop. 2006;54:79-96.

22. Saragosti E, Tchernov D, Katsir A, Shaked Y. Extracellular production and degradation of superoxide in the coral Stylophora pistillata and cultured Symbiodinium. PLos ONE. 2010;5:e12508.

23. Lesser MP. Oxidative stress causes coral bleaching during exposure to elevated temperatures. Coral Reefs. 1997;16:187-92.

24. Ladriere O, Compere P, Decloux N, Vandewalle P, Poulicek M. Morphological alterations of zooxanthellae in bleached cnidarian hosts. Cah De Biol Mar. 2008;49:215-27.

25. McGinty ES, Pieczonka J, Mydlarz LD. Variations in reactive oxygen release and antioxidant activity in multiple Symbiodinium types in response to elevated temperature. Microb Ecol. 2012;64:1000-7.

26. Dunn SR, Pernice M, Green K, Hoegh-Guldberg O, Dove SG. Thermal stress promotes host mitochondrial degradation in symbiotic cnidarians: are the batteries of the reef going to run out? PLos ONE. 2012;7:e39024.

27. Hawkins TD, Krueger T, Wilkinson SP, Fisher PL, Davy SK. Antioxidant responses to heat and light stress differ with habitat in a common reef coral. Coral Reefs. 2015;34:1229-41. 
28. Krueger T, Hawkins TD, Becker S, Pontasch S, Dove S, HoeghGuldberg $\mathrm{O}$, et al. Differential coral bleaching-contrasting the activity and response of enzymatic antioxidants in symbiotic partners under thermal stress. Comp Biochem Physiol a-Mol Integr Physiol. 2015;190:15-25.

29. Shick JM, Lesser MP, Jokiel PL. Effects of ultraviolet radiation on corals and other coral reef organisms. Glob Change Biol. 1996;2:527-45.

30. Schreiber U (2004). Pulse-amplitude-modulation (PAM) fluorometry and saturation pulse method: an overview. In: Papagiorgiou GG and Govindjee (eds). Chlorophyll a Fluorescence: Signature of Photosynthesis. Springer: Dordrecht, p 279-319.

31. Ralph PJ, Gademann R. Rapid light curves: a powerful tool to assess photosynthetic activity. Aquat Bot. 2005;82:222-37.

32. Stimson J, Kinzie RA. The temporal pattern and rate of release of zooxanthellae from the reef coral Pocillopora-damicornis (Linnaeus) under nitrogen-enrichment and control conditions. J Exp Mar Biol Ecol. 1991;153:63-74.

33. Halliwell B, Whiteman M. Measuring reactive species and oxidative damage in vivo and in cell culture: how should you do it and what do the results mean? Br J Pharmacol. 2004;142:231-55.

34. Cardenas L, Martinez A, Sanchez F, Quinto C. Fast, transient and specific intracellular ROS changes in living root hair cells responding to Nod factors (NFs). Plant J. 2008;56:802-13.

35. Kristiansen KA, Jensen PE, Moller IM, Schulz A. Monitoring reactive oxygen species formation and localisation in living cells by use of the fluorescent probe CM-H(2)DCFDA and confocal laser microscopy. Physiol Plant. 2009;136:369-83.

36. Xu J, Wang WY, Yin HX, Liu XJ, Sun H, Mi Q. Exogenous nitric oxide improves antioxidative capacity and reduces auxin degradation in roots of Medicago truncatula seedlings under cadmium stress. Plant Soil. 2010;326:321-30.

37. Schneider CA, Rasbnad WS, Eliceiri KW. NIH Image to ImageJ: 25 years of image analysis. Nat Methods. 2012;9:671-9.

38. Roberty S, Fransolet D, Cardol P, Plumier J-C, Franck F. Imbalance between oxygen photoreduction and antioxidant capacities in Symbiodinium cells exposed to combined heat and high light stress. Coral Reefs. 2015;34:1063-73.

39. Suggett DJ, Warner ME, Smith DJ, Davey P, Hennige S, Baker NR. Photosynthesis and production of hydrogen peroxide by Symbiodinium (Pyrrhophyta) phylotypes with different thermal tolerances. J Phycol. 2008;44:948-56.

40. Krieger-Liszkay A, Fufezan C, Trebst A. Singlet oxygen production in photosystem II and related protection mechanism. Photosynth Res. 2008;98:551-64.
41. Noctor G, Mhamdi A, Chaouch S, Han Y, Neukermans J, Marquez-Garcia B, et al. Glutathione in plants: an integrated overview. Plant Cell Environ. 2012;35:454-84.

42. Krueger T, Becker S, Pontasch S, Dove S, Hoegh-Guldberg O, Leggat W, et al. Antioxidant plasticity and thermal sensitivity in four types of Symbiodinium sp. J Phycol. 2014;50: 1035-47.

43. Repetto M, Semprine J, Boveris A (2012). Lipid peroxidation: chemical mechanism, biological implications and analytical determination. In: Catala A (ed). Lipid Peroxidation. InTech. p 3-30. Available from: https://www.intechopen.com/books/lipidperoxidation/lipid-peroxidation-chemical-mechanism-biologicalimplications-and-analytical-determination

44. Hillyer KE, Tumanov S, Villas-Bôas S, Davy SK. Metabolite profiling of symbiont and host during thermal stress and bleaching in a model cnidarian-dinoflagellate symbiosis. J Exp Biol. 2016;219:516-27.

45. Bindoli A. Lipid-Peroxidation in Mitochondria. Free Radic Biol Med. 1988;5:247-61.

46. Weng L-C, Pasaribu B, Lin IP, Tsai C-H, Chen C-S, Jiang P-L. Nitrogen deprivation induces lipid droplet accumulation and alters fatty acid metabolism in symbiotic dinoflagellates isolated from Aiptasia pulchella. Sci Rep. 2014;4:5777.

47. Hawkins TD, Krueger T, Becker S, Fisher PL, Davy SK. Differential nitric oxide synthesis and host apoptotic events correlate with bleaching susceptibility in reef corals. Coral Reefs. 2014;33:141-53.

48. Steward N, Martin R, Engasser JM, Goergen JL. A new methodology for plant cell viability assessment using intracellular esterase activity. Plant Cell Rep. 1999;19:171-6.

49. Tchernov D, Kvitt H, Haramaty L, Bibby TS, Gorbunov MY, Rosenfeld $\mathrm{H}$, et al. Apoptosis and the selective survival of host animals following thermal bleaching in zooxanthellate corals. Proc Natl Acad Sci USA. 2011;108:9905-9.

50. Rosic NN, Pernice M, Dove S, Dunn S, Hoegh-Guldberg O. Gene expression profiles of cytosolic heat shock proteins Hsp70 and Hsp90 from symbiotic dinoflagellates in response to thermal stress: possible implications for coral bleaching. Cell Stress Chaperones. 2011;16:69-80.

51. Middlebrook R, Anthony KRN, Hoegh-Guldberg O, Dove S. Heating rate and symbiont productivity are key factors determining thermal stress in the reef-building coral Acropora formosa. J Exp Biol. 2010;213:1026-34. 